class-structured society (as the established terminology will forever remind us), to that of a remorselessly efficient superorganism, to that of an endlessly squabbling nuclear family, and the conceptual emphasis has shifted from issues of reproductive altruism to issues of reproductive conflict.

Workers in most species of social Hymenoptera have potentially functional ovaries, but the average degree of ovarian development varies widely among and within species. ${ }^{7}$ Worker laying has become an act of care-giving in some species of ants and bees, where specialized trophic eggs are fed directly to developing larvae. But in many species, including some with trophic eggs, fully viable worker-laid eggs can also be produced. According to theory, workers should value sons (to whom they are related by $r=1 / 2)$ over brothers $(r=1 / 4)$; and, in species with single queens who mate only once, they should even prefer rearing nephews $(r=3 / 8)$ to rearing brothers. Consistent with theory, worker reproduction is believed to account for substantial proportions of males in some species ${ }^{8}$. But this merely sharpens the question why not in all?

One answer is that the queen 'suppresses' worker reproduction. Colonies in many species produce flushes of workerderived males following the death of the queen and, at a mechanistic level, the presence of a queen can inhibit the development of workers' ovaries ${ }^{8}$. But, at an evolutionary level, does this kind of 'control' equate to coercion or merely to signalling? In very small colonies, queens can bully workers and eat their eggs, but in the large colonies of socially advanced species such direct control is probably impossible. Theorists continue to search for devious (but evolutionarily stable) ways in which queens might coerce workers they seldom meet, but so far no really convincing mechanisms have been proposed.

Honeybees do not produce trophic eggs, yet a substantial minority of workers show slight ovarian development, with up to a few per cent showing development judged sufficient for egg-laying ${ }^{8}$. However, only a tiny minority (about 0.1 per cent) of males were worker-derived in a recent study, by Visscher ${ }^{9}$, of 11 colonies in which all workers were heterozygous for a visible genetic marker that revealed half of their offspring. This implies that few of the (presumptive) worker-laid eggs survived to adulthood. What happened to them?

Enter the self-appointed 'worker police'. If the queen mates only once then any worker prefers her sister's sons ( $r=$ $3 / 8)$ to her mother's sons $(r=1 / 4)$, and she therefore ought to be willing to rear worker-laid males in general, not just her own sons. But if her mother mated with several males, most of the worker's nestmates are half-sisters $(r=1 / 4)$ who produce half-nephews $(r=1 / 8)$; only a few are full sisters $(r=3 / 4)$ who produce full nephews $(r=3 / 8)$. Thus a worker's average relatedness to worker-derived males can drop well below her relatedness to queen-derived males; given a cost-effective means of doing so, she ought to block the production of worker-derived males ${ }^{10.14}$. Unless they could distinguish eggs or larvae that would give rise to full nephews from those that would give rise to halfnephews, all workers should agree that all worker-laid eggs (except their own, of course) must go. It is ironic that the queen's interests are also served by the universal back-stabbing that ensues.

Honeybees meet the key assumption of this model, because queens typically mate 10-20 times ${ }^{12}$. More generally, the model seems to be consistent with a pattern in which species with queens known to mate only once have substantial levels of worker reproduction (bumblebees and stingless bees for example), whereas species with queens known to mate several times have little worker reproduction (honeybees, yellowjackets) ${ }^{11}$. The report by Ratnieks and Visscher shows that the destruction of worker-laid eggs is a plausible mechanism of worker policing in honeybees. Workers removed almost all worker-laid eggs that were presented to them, but only a modest proportion of queen-laid eggs, and this discrimination was apparently not based on relatedness.

Like the thought police in George Orwell's Nineteen Eighty-Four, the drone police may be watching you at any time, because anyone might be a member. But perhaps it is not quite so simple. The experiments of Ratnieks and Visscher raise questions about both the origins and the consequences of differences between workers, most obviously between workers with and without developed ovaries, and in principle also between other groups that have yet to be defined.

Jon Seger is in the Department of Biology, University of Utah, Salt Lake City, Utah 84112 USA.

1. Ratnieks, F.L.W. \& Visscher, P.K. Nature 342, 796-797 (1989).

. Weismann, A. Contemp. Rev. 64, 309-338 (1893)

3. Spencer, H. Contemp. Rev. 64, 893-912 (1893).

4. Hamilton, W.D. J. theor. Biol. 7, 1-52 (1964).

5. Hamilton, W.D. A. Rev. Ecol. Syst. 3, 193-232 (1972).

6. Trivers, R.L. \& Hare, H. Science 191, 249-263 (1976).

7. Wilson, E.O. The Insect Societies (Harvard University Press, Cambridge, 1971)

8. Fletcher, D.J.C. \& Ross, K.G. A. Rev. Ent. 30, 319-343 (1985)

9. Visscher, P.K. Behav. Ecol. Sociobiol. 25, 247-254 (1989).

10. Starr, C.K. in Sperm Competition and the Evolution of Animal Mating Systems (ed. Smith, R.L.) 428-459 (AcaAnimal Mating demic, Orlando, 1984

11. Ratnieks, F.L.W. Am. Nat. 132, 217-236 (1988)

12. Laidlaw, H.H. \& Page, R.E. Jr Genetics 108, 985-997 (1984)

\section{A clean press}

THE traditional method of cleaning things is to agitate them in a liquid, detaching the dirt particles by viscous drag. It is extremely inefficient. The liquid boundary layer at a solid surface is always static, so that even the most violent agitation scarcely reaches the intimate surface where the dirt particles lurk.

The basic problem as Daedalus sees it is that liquids are incompressible. The ideal mode of agitation would expand the fluid away from the surface to be cleaned, dragging the dirt with it; but this is the one flow pattern forbidden to a liquid. So Daedalus proposes to use a compressible cleaning solvent - a supercritical fluid. Many supercritical fluids, like carbon dioxide, are already used industrially in various extractive processes. They are surprisingly good solvents. As a dry-cleaning fluid, carbon dioxide should dissolve quite a lot of dirt directly and suspend the rest.

A supercritical washing machine will need sturdy construction to withstand some 70 atmospheres of internal pressure. But by repeatedly raising and lowering that pressure in cloud-chamber fashion, it will force its supercritical solvent into a gentle but ideally efficient 'breathing' mode of agitation. Except for one mathematically inevitable fixed point, every element of the fluid will be driven in an expansive, radial flow pattern ideal for detaching dirt from solid surfaces.

Supercritical dry cleaning will be ecologically impeccable. No detergent will be needed or water wasted, carbon dioxide is more benign than any chlorocarbon and will clean amazingly quickly. Drying will be no problem, either. The carbon dioxide expands back to dry gas when the pressure is finally released. Simultaneously, all the suspended and dissolved dirt is precipitated. It will be filtered from the gas stream for possible re-use; maybe as fertilizer, or in the cases of foodwaste from dish washing, animal feed. Best of all, the cleaning effect can be intensified at will simply be increasing the depth of the pressure cycle.

For the ultimate in power laundering, the pressure could simply be released in one big blast, blowing the dirt away. Such forceful cleaning could open up whole new fields of renovation like instant paint stripping and derusting. A suitable supercritical solvent mixture might even strip printing ink from paper.

At last the major waste product of our bureaucratic, computer-ridden civilization could be effortlessly recycled. Printouts, memos, pamphlets, junk mail, newspapers, all could be instantly erased for re-use. Folds or creases could well be ironed out in the violence of the expansion, leaving pristine new paper. The separated dirt could be neatly recycled into more printing ink.

David Jones 